\title{
First-Episode Psychosis: A Clinical Approach
}

\author{
S. Charles Schulz, MD, Deanna Bass, MD, and Cynthia S. Vrabel, MD
}

Background: Psychotic illnesses, such as schizophrenia and bipolar illness, are relatively common and clearly devastating diseases. Most scientific literature focuses on research and care of patients suffering from psychotic illnesses in the middle age-group; subsequently, the first episode or early stages of psychotic illnesses have been relatively ignored, especially the issues of early diagnosis and intervention. The purpose of this article is to highlight issues of first-episode schizophrenia for the family physician and to discuss (1) diagnosis, (2) neuropsychiatry research, (3) new medications, and (4) family issues.

Metbods: To approach the issues of first-episode schizophrenia, we describe a case of a young woman who suffered her first episode of psychosis. Relevant literature related to the early stages of psychosis, including new pharmacologic treatments, is addressed.

Results: This report of our patient, a 19-year-old woman, illustrates the problems of a long prodromal phase of her illness, the use of medications that might have worsened her condition, and the successful use of new antipsychotic medications. Her family's issues as the patient went through this phase of her illness and recovery are reviewed.

Conclusions: Patients at the outset of a psychotic illness are frequently first seen by a family physician. Familiarity with current diagnostic criteria and effectiveness of new treatments can lead to improved detection and overall outcome. (J Am Board Fam Pract 2000;13:430-9.)

As for me, you must know, I shouldn't precisely bave chosen madness if there had been any choice. What consoles me is that I am beginning to consider madness as an illness like any other and that I accept it as such.

\section{-Vincent Van Gogh}

In the last 10 years there has been a marked increase in the research effort to explicate the pathophysiology of schizophrenia and to develop better treatments. For example, the National Plan for Schizophrenia Research ${ }^{1}$ highlighted the status of schizophrenia research and pointed to fruitful new opportunities. In addition, schizophrenia research has been a major focus of the Decade of the Brain initiative. There have been exciting findings as a result of brain-imaging research, even to the point of visualizing through functional-imaging

Submitted, revised, 23 March 2000.

From the Department of Psychiatry (SCS, DB) and the Department of Family Practice \& Community Health (DB), University of Minnesota School of Medicine, Minneapolis; and the Department of Psychiatry (CSV), Case Western Reserve University School of Medicine, and Department of Psychiatry (CSV), University Hospitals of Cleveland, Cleveland. Address reprint requests to S. Charles Schulz, MD, Department of Psychiatry, University of Minnesota, F282/2A West, 2450 Riverside Ave, Minneapolis, MN 55454. methods, how the brain works on standardized tasks. ${ }^{2,3}$ With improved genetic methodologies, both in molecular as well as statistical laboratories, there is a greater appreciation of the locus of the genetic contribution to schizophrenia. ${ }^{4}$

Perhaps of greatest immediate importance has been the introduction of fundamentally different, new antipsychotic medications for schizophrenia. The first of these new medications, clozapine, was introduced in the United States in 1990. Kane et $\mathrm{al}^{5}$ showed that clozapine was effective for patients who failed treatment with older medicines. Clozapine is described as an atypical antipsychotic because it reduces symptoms of psychosis without causing movement disorder side effects-the dystonic or parkinsonian effects that are common with the traditional antipsychotic medications. Unfortunately, clozapine is associated with a $1 \%$ rate of agranulocytosis and is not used as a front-line treatment. Since the introduction of clozapine, three other atypical or new antipsychotics have been released for front-line treatment. The first was risperidone, ${ }^{6}$ a medicine with low levels of movement side effects in appropriate dose ranges that is effective against symptoms of psychosis. Olanzapine was the second, and it has been available since the autumn of $1996 .{ }^{7}$ Third was quetiapine, released in late 1997 after two pivotal studies showed efficacy and safety. 8,9 
Despite the research focus on schizophrenia and the introduction of new treatments, less attention has been paid to the early stages of the illness. As this case presentation and discussion are intended to illustrate, however, first-episode schizophrenia can be objectively and reliably distinguished from other conditions, and new medications can lead to improved outcomes. These new treatments have focused attention on the importance of early detection and initiation of therapy. We believe it is important that family physicians be alert to and recognize psychotic symptoms in adolescents and young adults. We also believe it is important that family physicians treat such symptoms using the new antipsychotic medications, alone or in combination with other medications, as described below. Furthermore, especially for primary care physicians, there is an increasing awareness of the special needs of the whole family.

\section{Methods}

We describe a case of a young woman who suffered her first episode of psychosis. Relevant literature related to the early stages of psychosis, including new pharmacologic treatments, was researched using the key words "schizophrenia," "schizo affective," and "antipsychotics," and is addressed.

\section{Case Report}

An 18-year-old single woman came to the inpatient psychiatric unit at University Hospitals of Cleveland complaining of depressed mood, blunted affect, psychomotor retardation, suicidal ideation, auditory hallucinations, and delusions of paranoia and thought control. Her chief complaint was "I feel like I don't have a brain inside my head."

\section{History of the Present Illness}

It appeared that the first symptoms of illness occurred 7 months before her admission. At that time she had just completed her first year of college. In high school she had been a gifted athlete, a talented musician, and an excellent student. She did not use alcohol or drugs. Her psychiatric history was notable only for an acute stress disorder, which occurred after a bicycle accident and responded to psychotherapy. Her medical history was notable for two nonfebrile generalized seizures in childhood, which were treated with carbamazepine. She did not suffer from temporal lobe epilepsy.
At the end of her freshman year, her family noted the gradual onset of anxiety symptoms and mild suspiciousness (feeling that her friends had changed and no longer liked her because she was too popular). She was fired from her job at a local retailer after her boss observed that she would often "stand around staring and doing nothing." These symptoms prompted a visit to her pediatrician, who was concerned about the possibility of depression versus seizures. Her carbamazepine level measured at that time was therapeutic.

During the next month the patient became more preoccupied and withdrawn, often to the point of being unable to engage in conversation. She reported auditory hallucinations with religious content. Her paranoid delusions progressed to the point where she frequently did not feel safe and was unable to trust her family. Her behavior became driven by the paranoia (barricading herself in the basement, placing marbles on the stairs to stop intruders, and telephoning 911 with fears of someone being "after me"). During this period she was evaluated by neurologist, who ordered a magnetic resonance imaging scan (MRI) and an electroencephalogram (EEG), the results of which were normal. She was also evaluated by a psychiatrist and a psychologist. The month culminated in an admission to the psychiatric unit of a local hospital after the patient ran away from home and was missing for 36 hours (behavior quite uncharacteristic for her).

When admitted to the psychiatric unit, the patient refused all medications and was discharged after 24 hours. She remained agitated and paranoid. The auditory hallucinations became more prominent (derogatory accusations and two voices commenting on her behavior). On the day after she left the hospital, she was readmitted to the psychiatric unit of another local hospital after running to a police station to report that she was being abused. The admitting diagnosis was "paranoid disorder, possibly schizophrenia." She was given a typical antipsychotic (haloperidol), with some improvement; however, she subsequently refused medications and was discharged after a 2-week hospitalization.

During the next several weeks the patient showed progressively worsening agitation, insomnia, paranoia, and bizarre behavior. Her third admission to the psychiatric unit occurred after she ran away from home, discarded her personal be- 
longings, and was found wandering wet and disheveled 15 miles from her home. On the day after admission she was transferred to a state psychiatric facility. The admitting diagnosis was "major depressive disorder with psychotic features." She was given an antidepressant (nefazodone hydrochloride) with some improvement in concentration.

She was discharged after a 2-week hospitalization and immediately discontinued her medication. One week later she took a multiple-drug overdose in a psychotically motivated suicide attempt ("I felt like the chemicals in my brain were crazy ... like too many personalities were trying to get out; I was controlled by them"). She was briefly cared for in the medical intensive care unit and subsequently transferred back to the state psychiatric facility.

During a 9-week hospital stay, she was given several antidepressants (selective serotonin reuptake inhibitors) and several typical antipsychotics for brief periods without improvement. The progression of her psychiatric illness was apparent as evidenced by continued delusional thinking, auditory hallucinations involving commands from the voice of Satan, poor hygiene, blunted affect, and social withdrawal. Concerned by the obvious decline in their daughter's condition, her parents contacted University Hospitals of Cleveland for a second opinion.

At that time we admitted the patient to the inpatient psychiatric unit and were told she had an initial diagnosis of schizoaffective disorder based on prominent affective and psychotic symptoms that fulfilled criteria from the Diagnostic and Statistical Manual of Mental Disorders (ed 4) (DSM IV). ${ }^{10}$ She began taking an antidepressant (sertraline) and an atypical antipsychotic (risperidone). Carbamazepine was continued as an anticonvulsant. During the course of a 3-week hospitalization, the patient's psychotic and depressive symptoms steadily improved. An episode of catatonia emerged that did not respond to benzodiazepines but was successfully treated with a course of electroconvulsive therapy. After her discharge from the inpatient unit, she attended a daily partial hospitalization program for 1 month. At that time she was no longer experiencing hallucinations, delusions, or subjective complaints of depression. She continued to have a blunted affect, ambivalence, and difficulty with complex tasks requiring sustained attention. Neuropsychologic testing was undertaken to help her make decisions regarding education and employment.

Eight months after the onset of her symptoms, our patient was discharged from partial hospitalization to the outpatient clinic of one of the authors (CSV). Her mental status remained stable on antidepressant (sertraline $150 \mathrm{mg} / \mathrm{d}$ ), atypical antipsychotic (risperidone $6 \mathrm{mg} / \mathrm{d}$ ), and anticonvulsant (sodium divalproex $1,000 \mathrm{mg} / \mathrm{d}$ ) medications. She continued to improve during the course of treatment. She resumed her studies at a local university (achieving As and Bs) and worked part time at a local retailer.

In summary, this 18-year-old woman sought treatment for an initial onset of a 7-month course of progressively worsening psychosis and intermittent depression, which responded to definitive treatment with atypical antipsychotic and antidepressant medications.

\section{Discussion}

This case was chosen because it illustrates many early-stage issues of schizophrenia. Our discussion will focus on the following: (1) the symptomatology and diagnosis of psychosis at the outset of the illness, (2) the epidemiology of early-stage schizophrenia, (3) a brief description of studies investigating biologic findings at the outset of the illness showing that early stages of schizophrenia are part of the adult disease, (4) treatment with new agents and use of augmenting medications, and (5) approaches to families' concerns. We feel these five points are important to family physicians because they are often the first physicians contacted by a family when symptoms emerge.

\section{Pbenomenology and Diagnosis}

For many years psychiatrists have struggled with the phenomenology of psychosis in adolescents and young adults. Not wanting to overdiagnose schizophrenia or other psychotic disorders (eg, major depression with psychotic features), the field has not been aggressive in recognizing psychosis at the outset. Our research experience with adolescents with psychosis has shown that school counselors, primary care physicians, and church leaders are also reluctant or are not fully knowledgeable about the signs of schizophrenia and their importance, as is clearly illustrated in the case described. Our patient 
Table 1. Psychiatric Disorders With Psychotic or Mood Symptoms.

\begin{tabular}{|c|c|c|}
\hline Disorder & Psychotic Symptoms & Mood Symptoms \\
\hline Schizophrenia DSM IV 295 & $\begin{array}{l}\text { Psychotic symptoms present for } 6 \\
\text { months. Auditory hallucinations, } \\
\text { delusions, and disorganized thinking } \\
\text { are prominent }\end{array}$ & $\begin{array}{l}\text { Facial expression is frequently flat, but } \\
\text { patient does not report sadness. } \\
\text { Depression frequent after resolution of } \\
\text { psychosis }\end{array}$ \\
\hline Bipolar disorder DSM IV 296 & $\begin{array}{l}\text { Psychotic symptoms are mood } \\
\text { congruent. Belief that one is God } \\
\text { during manic stage }\end{array}$ & $\begin{array}{l}\text { Prominent grandiosity, rapid speech, and } \\
\text { decreased sleep when mood is elevated. } \\
\text { Psychomotor retardation, hopelessness, } \\
\text { or suicidal when low }\end{array}$ \\
\hline Schizoaffective disorder DSM IV 295.7 & $\begin{array}{l}\text { Same as noted for schizophrenia. } \\
\text { Diagnosis of schizoaffective disorder } \\
\text { when criteria for both parts of the } \\
\text { disorder are met }\end{array}$ & Same as for bipolar disorder \\
\hline $\begin{array}{l}\text { Major depression with psychotic features } \\
\text { DSM IV 296.XX (code modified for } \\
\text { severity and presence of psychosis) }\end{array}$ & $\begin{array}{l}\text { Psychotic symptoms are mood } \\
\text { congruent, eg, voices are morbidly } \\
\text { derogatory }\end{array}$ & $\begin{array}{l}\text { Sad and helpless feelings, decreased } \\
\text { appetite, interrupted sleep, and suicidal } \\
\text { thoughts }\end{array}$ \\
\hline
\end{tabular}

Note: psychosis is regarded as loss of touch with reality, characterized by hallucinations, delusions (fixed, false beliefs), disorganized thinking, and bizarre behavior.

DSM IV - Diagnostic and Statistical Manual of Mental Disorders, ed 4.

initially had a mood disorder diagnosed despite her clear psychotic symptoms.

The 1994 DSM IV, the result of substantial nosological study, has indicated that the criteria for schizophrenia are the same at the onset of the illness as at later times. In the past, psychiatry had been criticized for a lack of diagnostic reliability, but agreement among psychiatrists in making the diagnosis of schizophrenia is quite high-even in its early states. The work of Carlson et al, ${ }^{11}$ who have investigated diagnosis in a "first break" sample, shows not only high interrater reliability of psychotic symptoms at first assessment, but also high stability of diagnosis during the first 6 months. This latter finding is important in its treatment implications for the early stages of schizophrenia, because clinicians need not think they should wait long periods for the diagnostic picture to unfold before starting treatment. It should be noted here that not all psychotic conditions in adolescents and young adults are schizophrenia. Other disorders include psychosis, however, they, too, can be objectively and reliably assessed. ${ }^{12}$

Distinguishing among psychotic disorders that appear during adolescence and young adulthood is important, but we believe the distinction can be made by the family physician. The major categories of psychotic disorders that can appear in youth and their mood and psychotic symptoms are listed in Table 1. Further information about distinguishing these disorders can be found in the DSM IV section on algorithms. ${ }^{10}$
In the case described above, a diagnosis of schizoaffective disorder was delayed despite clear symptoms of the disorder, which led to delay in appropriate pharmacologic intervention and a resulting prolonged stay in an inpatient setting. In addition to the long time the patient suffered from symptoms of psychosis, a great amount of time passed during an important developmental phase for this young woman.

\section{Epidemiology}

Even though schizophrenia is not a rare illness (it strikes $1 \%$ of the US population ${ }^{13}$ ), there is a perception that schizophrenia is mainly an adult disorder. This perception is not true. Loranger ${ }^{14}$ reported that $39 \%$ of men and $23 \%$ of women have had the onset of psychotic symptoms before 19 years of age. Studying a German catchment area, Hafner et $\mathrm{al}^{15}$ found that most men had onset of schizophrenia before they were 24 years old and most women before 26 years old.

Although this article focuses on schizophrenia, it should be noted that the other psychotic disorders have their onset in adolescence or young adulthood as well. Our experience has been that initial episodes occur during the school years, work, or military service, during a time when these persons might be in contact with school counselors, family physicians, pediatricians, or other health workers. One factor included in making the diagnosis of schizophrenia at the first episode is the prodromal period of nonspecific symptoms-decreased school 
Table 2. Traditional and New Antipsychotic Medications.

\begin{tabular}{|c|c|c|c|}
\hline Name (Brand) & Neurologic Side Effects & Nonneurologic Side Effects & Dose \\
\hline Haloperidol (Haldol) ${ }^{\star}$ & $\begin{array}{l}\text { Dystonia in early use } \\
\text { Parkinsonism } \\
\text { Tardive dyskinesia ( } 5 \% \text { of } \\
\text { cases per year of treatment) } \\
\text { Seizures (rarely) } \\
\text { Neuroleptic malignant } \\
\text { syndrome }\end{array}$ & $\begin{array}{l}\text { Occasional sexual side effects } \\
\text { (galactorrhea or impotence) } \\
\text { Sedation }\end{array}$ & $\begin{array}{l}\text { Adult: } 10-20 \mathrm{mg} / \mathrm{d} \\
\text { Early-stage illness: } 2-10 \mathrm{mg} / \mathrm{d}\end{array}$ \\
\hline Risperidone (Risperdal) & $\begin{array}{l}\text { Extrapyramidal side effects at } \\
\text { doses }>6 \mathrm{mg} / \mathrm{d} \\
\text { Neuroleptic malignant } \\
\text { syndrome reported } \\
\text { Tardive dyskinesia }<1 \% \text { per } \\
\text { year }\end{array}$ & $\begin{array}{l}\text { Sexual side effects secondary to } \\
\text { hyperprolactinemia in some } \\
\text { patients, eg, galactorrhea in } \\
\text { some young patients } \\
\text { Some weight gain }\end{array}$ & $\begin{array}{l}\text { Average adult: } 4-6 \mathrm{mg} / \mathrm{d} \\
\text { Early-stage illness: } 2-4 \mathrm{mg} / \mathrm{d}\end{array}$ \\
\hline Olanzapine (Zyprexa) & $\begin{array}{l}\text { Extrapyramidal side effects at } \\
\text { higher doses }(\mathrm{eg}, 25 \mathrm{mg} / \mathrm{d}) \\
\text { Tardive dyskinesia } \leq 1 \%\end{array}$ & $\begin{array}{l}\text { Sedation } \\
\text { Weight gain }\end{array}$ & $\begin{array}{l}\text { Average adult: } 12.5-70 \mathrm{mg} / \mathrm{d} \\
\text { Early-stage illness } 10-20 \mathrm{mg} / \mathrm{d}\end{array}$ \\
\hline Quetiapine (Seroquel) $^{\dagger}$ & $\begin{array}{l}\text { Extrapyramidal side effects } \\
\text { rare } \\
\text { Tardive dyskinesia is rare }\end{array}$ & $\begin{array}{l}\text { Sedation } \\
\text { Some weight gain }\end{array}$ & $\begin{array}{l}\text { Adult: } 400-600 \mathrm{mg} / \mathrm{d} \\
\text { Early-stage illness: } 200-600 \mathrm{mg} / \mathrm{d}\end{array}$ \\
\hline Clozapine (Clozaril) & $\begin{array}{l}\text { Extrapyramidal side effects } \\
\text { does not occur } \\
\text { Akathisia (recessedness has } \\
\text { been reported) } \\
\text { Tardive dyskinesia probably } \\
\text { absent }\end{array}$ & $\begin{array}{l}\text { Agranulocytosis } \\
\text { Sedation } \\
\text { Hypothermia }\left(100^{\circ} \mathrm{F}\right)\end{array}$ & Adult: $300-600 \mathrm{mg} / \mathrm{d}$ \\
\hline
\end{tabular}

Haloperidol listed as representative of a nonsedating traditional antipsychotic medication.

${ }^{\dagger}$ Quetiapine is a relatively new agent. Tardive dyskinesia frequency is not yet known. Although the Physicians Desk Reference recommends eye examination, no increased frequency of cataracts are found in human studies.

or work performance, diminished attention abilities, social avoidance, and so on. The prodromal period, which can last for 1 year or more before specific schizophrenic symptoms emerge, is obviously troubling for young people and their parents. Looking back at our patient's history, her prodrome probably began on her return from her freshman year, when she was anxious and suspicious.

The issue of the prodromal period and treatment lag (the time from symptoms to treatment) has been addressed in a recent study undertaken in Vancouver. ${ }^{16}$ The investigators found a median of 8 weeks and a mean of 52 weeks of treatment lag. A long treatment lag is important because of unnecessary suffering; it also is of concern because studies during the last decade indicate such a lag might confer poorer response to treatment as measured by length of time to remission and level of response. ${ }^{17}$ Restated, the longer a youngster is symptomatic, the longer it takes to achieve remission. These recent findings have motivated programs and campaigns of public health education and early intervention to give adolescents and young adults the greatest chance of a good outcome.

Especially important for the early stages of schizophrenia is the epidemiologic finding of an associated $10 \%$ rate of completed suicides. ${ }^{18}$ This finding underscores the seriousness of and mortality associated with schizophrenia, and it is hoped that early recognition and prompt treatment can lead to a decrease in the suicide rate. In our young patient, depression had been a major factor in addition to her psychosis, so that her clinicians would need to be aware of the potential for suicide. Furthermore, follow-up studies have shown substantial morbidity in schizophrenic patients suffering from depression. In a follow-up study of adolescent schizophrenic patients, Krausz and Muller-Thom$\operatorname{sen}^{19}$ reported that depression, anxiety, and suicidal thoughts were the major concerns of the patients. For this reason recognition and treatment of comorbid depression are important parts of this patient's treatment. 


\section{Patbopbysiology}

Forty years ago American psychiatrists generally agreed that schizophrenia was the result of difficulties in early life-generally a result of relationship or communication difficulties with parents. As noted earlier, substantial progress has been made to extend the understanding of genetic, neurodevelopmental, neurotransmitter, and cognitive aspects of schizophrenia. Specifically, reports of studies using a genome scan now indicate that portions of chromosomes 5, 6, 8, 10, 13 and 22 are statistically associated with increasing the risk of schizophrenia. ${ }^{20-24}$ These are exciting and interesting leads, yet the amount of increased risk for any one of the chromosomal areas is small. Genetic researchers believe that identification of a gene in any one of these areas could lead to a better understanding of pathophysiology of schizophrenia.

Early brain-imaging studies of schizophrenia assessed general measures, such as the size of the lateral ventricles. ${ }^{25}$ With the advent of MRI, which allows for excellent brain morphology analysis, it appears that the frontal lobes, along with the hippocampus (medial temporal lobe), are the areas of the brain most effected. ${ }^{26}$ Recent studies measuring the thalamus have shown its size to be reduced in schizophrenic compared with control patients. ${ }^{27}$ Taken as a whole, the brain-imaging studies have not shown that these structural parameters change with time, and thus schizophrenia is hypothesized as most likely a neurodevelopmental disorder. ${ }^{28}$

All the effective antipsychotic medications have dopamine-blocking action, whether as their primary activity, as with the traditional antipsychotics, or as only a part of the activity (less than serotonin blockade), as with the new, atypical antipsychotics. The discovery of dopamine-blocking capabilities of antipsychotic medications led to the dopamine hypothesis of schizophrenia. ${ }^{29}$ More recently, the role of serotonin in the pathophysiology of schizophrenia has been examined.

During the last 15 years, adolescents and young adults have been studied by researchers using a number of neuropsychiatric paradigms. Our work with teenagers has shown that for those with schizophrenia, findings on computed tomograms $(\mathrm{CT})^{30}$ and MRI scans ${ }^{31}$ are different from those of control patients, a finding similar to that of Frazier et $\mathrm{al},{ }^{32}$ who assessed adolescents with childhoodonset schizophrenia. In young adults, MRI scan studies have shown enlarged ventricles at first hos- pitalization..$^{33,34}$ In addition to structural changes seen on imaging, first-episode young patients have substantially poorer neuropsychologic function (attention, memory, decision making) than a control population. ${ }^{35,36}$ Our group has extended these observations into the adolescent patient group. ${ }^{37}$

These findings are important for clinicians because they underscore the biologic continuity between the early stages of schizophrenia and the adult stages of the illness. Furthermore, these research assessments underscore the seriousness of psychosis and refute ideas of early schizophrenia as a developmental stage or stress reaction. Our patient had many difficulties noted on her neuropsychologic assessment, ranging from difficulty with attention to memory loss. When the pathophysiologic components are ignored, treatment planning is frequently inadequate. In other words, the mood and psychotic symptoms experienced by our patient are not psychologic in nature. Instead, they result from brain structural (perhaps microstructural) and neurotransmitter disturbances.

\section{Treatment}

In our opinion, clinicians have been reluctant to be aggressive in initiating pharmacologic treatment of schizophrenia at the early stages. In addition to issues already raised, there are two more specific factors. One is the lack of data on the use of antipsychotic medication in adolescent and young adult patients. The other, and more important factor, has been the substantial side effects and lack of patient acceptance of the traditional antipsychotic medications (eg, chlorpromazine, thioridazine, and haloperidol).

Only two controlled trials have investigated traditional medications on schizophrenic adolescents, the age-group of our patient. The placebo-controlled trial by Pool et $\mathrm{al}^{38}$ showed that a traditional antipsychotic (loxapine) was effective compared with placebo and had minimal side effects. As was common for studies at that time, only positive psychotic symptoms (hallucination and delusions) were assessed. In the other controlled trial (thioridazine vs thiothixene), Realmuto et $\mathrm{al}^{39}$ showed that both traditional medications significantly reduced symptoms from baseline. Interestingly, they noted in their discussion that, although the medications were effective, it was difficult to balance side effects with efficacy. They frequently found that patients had movement disorder side effects which stood in 
the way of reaching an effective dose (neuroleptic intolerance). There are few antipsychotic studies of patients at the outset of their illness. In a major first-episode study by Lieberman and colleagues, ${ }^{40}$ $83 \%$ of patients achieved a remission during the first year of treatment while taking traditional antipsychotic medications, thus indicating a good outcome for patients when they are first seen.

For the new antipsychotic medications, case reports and trials involving patients at the early stage of illness are just now being presented and published. In teenagers, an early report ${ }^{41}$ noted the usefulness and safety of risperidone for psychotic disorders. In adolescents with schizophrenia, Grcevich et al ${ }^{42}$ described the cases of 16 teenagers taking risperidone who showed a significant decrease in both positive and negative symptoms of schizophrenia. The clinical impression was that the medication was well accepted by a young group.

For the recently released new antipsychotic olanzapine, an analysis of a group of first-episode patients who were part of a larger olanzapine-vshaloperidol trial showed equivalent efficacy and fewer side effects. Negative symptoms (apathy, emotional blunting, and social isolation, for example) improved more with olanzapine. ${ }^{7}$

Quetiapine is the newest atypical antipsychotic medication. As a result of its pattern of efficacy and safety in adults, clinicians can expect to see it used in young patients as a first-line treatment. A recent study has shown symptom reduction and few movement side effects in adolescents with psychotic illnesses. ${ }^{43}$

Clinicians and researchers working with the new medications in patients at an early stage of schizophrenia note efficacy and few side effects. Coupled with the impression of decreased negative symptoms, the new medications can allow clinicians to be more assertive in disease recognition and treatment.

To date there are no clear guidelines for selecting one agent rather than another. All three of the new, front-line, atypical antipsychotic medications are significantly more effective than placebo and in some studies are significantly more effective than haloperidol. Head-to head comparisons are sparse, and the results to date are mixed. Perhaps more importantly, what is the role of the family physician who is caring for a stabilized young person? We believe there are many important tasks, including (1) maintaining good physical health, (2) being mindful of antipsychotic medications side effects that can lead to added treatment or changing medications, and (3) being aware of potential drug-drug interactions.

A concern for psychiatrists and family physicians has been cost, as the new agents are substantially more expensive than the traditional medications. Interestingly, studies have shown that the new medications lead to substantial decreases in hospital days, which more than offset medication costs. ${ }^{44}$ Fortunately, most state Medicaid programs have coverage for the new, atypical medications, making them available to young patients with a psychotic illness. The new medications, even though more expensive, are substantially different and superior to the older medications, leading us to recommend them as the treatment of choice for the new patient.

For our patient, we believe the new medication risperidone has offered effective and safe treatment. Although our patient represents a single case, risperidone appears to have been better tolerated than haloperidol and has led to better compliance-a problem that characterized her early course. Because she has been able to return to school, we think the new medications have allowed her to participate more fully.

This patient received an antidepressant medication along with the new antipsychotic medication. This combination is frequently used for schizoaffective disorder or major depression with psychotic features (psychotic depression). Furthermore, research in the last decade has pointed to the importance of using an antipsychotic-antidepressant combination for symptoms of depression in a schizophrenic patient. Recall the high suicide rate in this population. For the patient with bipolar dișorder who has manic episodes, a mood-stabilizing agent (lithium, valproate, or other) is usually used alone. If psychotic symptoms are present, an antipsychotic mediation (preferably the new atypical agents) is also prescribed.

There are at least three major reasons why a family physician should be willing to treat psychosis in a young person: (1) The patient might not be able to see a psychiatrist for weeks, and early intervention for psychosis is important. (2) The patient might be comfortable only with the family physician and refuse to see a psychiatrist. (3) Psychiatric referral might not be possible, especially in a rural area. For this last point, telemedicine projects might prove useful. 
Schizophrenia and the related disorders described in this article have multiple possible parts. The family physician can focus on the positive psychotic symptoms by prescribing antipsychotic medications and creating a calm and safe environment. If the family physician becomes aware of cognitive difficulties, as were observed in our patient, then job training, special school schedules, and social skills training can be helpful. Recent research has drawn attention to negative symptoms of schizophrenia-flattened affect, lack of motivation, decreased pleasure - and their relation to poor outcome. Community resources, such as Department of Rehabilitation and Case Management, might help in this area.

\section{Families of Patients with First-Episode Psychosis}

During the last 15 years there has been a growing collaboration between families who have a relative with schizophrenia and clinicians, mostly through the National Alliance for the Mentally Ill (NAMI). The field still has a poor understanding of the shock and grief that result from having a son, daughter, or sibling with a diagnosed psychotic disorder. We have noticed in our work with teenager's parents that they struggle considerably with the onset of their child's psychosis, often reacting with guilt and denial. Both psychiatrists and primary care physicians should be sensitive to the impact of the onset of psychosis on the family, which has a burden comparable to that of other severe medical illnesses. ${ }^{45}$ Another reaction is that families become confused about where to turn and how to get help. Many young patients have been taken to a long series of clinicians before seeing a psychiatrist. This pattern can lead to further confusion and delay or inappropriate treatment. The family physician can break this cycle of a family's search for answers by recognizing the symptoms of schizophrenia and helping the patient and family to start appropriate treatment.

The main role for the family physician is to be aware of the phases of shock, denial, guilt, and confusion that many families experience. It will then be possible to help the family through understanding and supportive comments or referral for counseling.

Our clinical team has always included the family in treatment planning. We offer a gradual education program about schizophrenia and medication treatment as well as support counseling. We believe these interventions have reduced family morbidity and helped the patient comply with the treatment plan. Further research in this area will help guide the field toward optimal interventions.

\section{Summary}

We have described the case of a young woman at the onset of a schizoaffective disorder to illustrate a number of issues about the early stage of the illness and to provide an update of advances that relate to first-episode psychosis. Establishment of the reliability and stability of diagnosis, improvements in pharmacologic treatment, and a greater appreciation of family issues all bode well for better outcomes for these patients. In addition, recent studies showing the negative impact of a prolonged treatment lag make increased awareness of the issues surrounding schizophrenia and related disorders all the more important. Many families relate the onset of psychosis to a primary physician before seeking additional care. We hope a grater appreciation of the signs and symptoms of psychosis and the advances in treatment will allow for more assertive early intervention.

\section{References}

1. Keith SJ, Regier DA, Judd LL. A national plan for schizophrenia research: report of the National Advisory Mental Health Council. Rockville, Md: Alcohol, Drug Abuse, and Mental Health Administration, National Institute of Mental Health, Department of Health \& Human Services. 1988.

2. Weinberger D, Berman KF, Zec RF. Physiologic dysfunction of dorsolateral prefrontal cortex in schizophrenia. I. Regional cerebral blood flow evidence. Arch Gen Psychiatry 1986;43:114-24.

3. Liddle PF. Functional imaging -schizophrenia. $\mathrm{Br}$ Med Bull 1996;52:486-94.

4. Kendler KS, MacLean CJ, O'Neill FA, et al. Evidence for a schizophrenia vulnerability locus on chromosome 8p in the Irish Study of High-Density Schizophrenia Families. Am J Psychiatry 1996;153: 1534-40.

5. Kane J, Honigfeld G, Singer J, Meltzer H. Clozapine for the treatment-resistant schizophrenic. A doubleblind comparison with chlorpromazine. Arch Gen Psychiatry 1988;45:789-96.

6. Marder SR, Meibach RC. Risperidone in the treatment of schizophrenia. Am J Psychiatry 1994;151: $825-35$.

7. Tollefson GD, Beasley CM Jr, Tran PV, et al. Olanzapine versus haloperidol in the treatment of schizophrenia and schizoaffective and schizophreniform 
disorders: results of an international collaborative trial. Am J Psychiatry 1997;154:457-65.

8. Small JG, Hirsch SR, Arvanitis LA, Miller BG, Link CG. Quetiapine in patients with schizophrenia. A high- and low-dose double-blind comparison with placebo. Seroquel Study Group. Arch Gen Psychiatry $1997 ; 54: 549-57$.

9. Arvanitis LA, Miller BG. Multiple fixed doses of "Seroquel" (quetiapine) in patients with acute exacerbation of schizophrenia: a comparison with haloperidol and placebo. The Seroquel Trial 13 Study Group. Biol Psychiatry 1997;42:233-46.

10. Diagnostic and statistical manual of mental disorders (4th ed). Washington, DC: American Psychiatric Association, 1994.

11. Carlson GA, Fennig S, Bromet EJ. The confusion between bipolar disorder and schizophrenia in youth: where does it stand in the 1990s? J Am Acad Child Adolesc Psychiatry 1994:33:453-60.

12. McKenna K, Gordon CT, Lenane M, Kaysen D, Fahey K, Rapoport JL. Looking for childhood-onset schizophrenia: the first 71 cases screened. J Am Acad Child Adolesc Psychiatry 1994;33:636-44.

13. Regier DA, Boyd JH, Burke JD Jr, et al. One-month prevalence of mental disorders in the United States based on five epidemiologic catchment area sites. Arch Gen Psychiatry 1988;45:977-86.

14. Loranger AW. Sex difference in age at onset of schizophrenia. Arch Gen Psychiatry 1984;41:15761.

15. Hafner H, Maurer K, Loffler W, Riecher-Rossler A. The influence of age and sex on the onset and early course of schizophrenia. Br J Psychiatry 1993;162: 80-6.

16. Beiser M, Erickson D, Fleming JA, Iacono WG. Establishing the onset of psychotic illness. Am J Psychiatry 1993;150:1349-54.

17. Loebel AD, Lieberman JA, Alvir JM, Mayerhoff DI, Geisler SH, Szymanski SR. Duration of psychosis and outcome in first-episode schizophrenia. Am J Psychiatry 1992;149:1183-8.

18. Fenton WS, Mosher LR, Herrell JM, Blyler CR. Randomized trial of general hospital and residential alternative care for patients with severe and persistent mental illness. Am J Psychiatry 1998;155:51622.

19. Krausz M, Muller-Thomsen T. Schizophrenia with onset in adolescence: an 11-year follow-up. Schizophr Bull 1993;19:831-41.

20. Kendler KS, MacLean CJ, Ma Y, O'Neill FA, Walsh D, Straub RE. Marker-to-marker linkage disequilibrium on chromosomes $5 \mathrm{q}, 6 \mathrm{p}$, and $8 \mathrm{p}$ in Irish highdensity schizophrenia pedigrees. Am J Med Genet 1999;88:29-33.

21. Straub RE, MacLean CJ, Martin RB, et al. A schizophrenia locus may be located in region 10p15-p11. Am J Med Genet 1998;81:296-301.
22. Wildenauer DB, Schwab SG. Chromosomes 8 and 10 workshop. Am J Med Genet 1999;88:239-43.

23. Blouin JL, Dombroski BA, Nath SK, et al. Schizophrenia susceptibility loci on chromosomes $13 \mathrm{q} 32$ and 8p21. Nat Genet 1998;20:70-3.

24. Chow EW, Mikulis DJ, Zipursky RB, Scutt LE, Weksberg R, Bassett AS. Qualitative MRI findings in adults with $22 \mathrm{q} 11$ deletion syndrome and schizophrenia. Biol Psychiatry 1999;46:1436-42.

25. Weinberger DR, Torrey EF, Neophytides AN, Wyatt RJ. Lateral cerebral ventricular enlargement in chronic schizophrenia. Arch Gen Psychiatry 1979; 36:735-9.

26. McCarley RW, Wible CG, Frumin M, et al. MRI anatomy of schizophrenia. Biol Psychiatry 1999;45: 1099-119.

27. Andreasen NC, Arndt S, Swayze V 2nd, et al. Thalamic abnormalities in schizophrenia visualized through magnetic resonance image averaging. Science 1994;266:294-8.

28. Weinberger DR. Implications of normal brain development for the pathogenesis of schizophrenia. Arch Gen Psychiatry 1987;44:660-9.

29. Carlsson A. Antipsychotic drugs, neurotransmitters, and schizophrenia. Am J Psychiatry 1978;135:16573.

30. Schulz SC, Koller MM, Kishore PR, Hamer RM, Gehl JJ, Friedel RO. Ventricular enlargement in teenage patients with schizophrenia spectrum disorder. Am J Psychiatry 1983;140:1592-5.

31. Friedman L, Findling RL, Kenny JT, et al. An MRI study of adolescent patients with either schizophrenia or bipolar disorder as compared to healthy control subjects. Biol Psychiatry 1999;46:78-88.

32. Frazier JA, Giedd JN, Hamburger SD, et al. Brain anatomic magnetic resonance imaging in childhoodonset schizophrenia. Arch Gen Psychiatry 1996;53: 617-24.

33. DeLisi LE, Hoff AL, Schwartz JE, et al. Brain morphology in first-episode schizophrenic-like psychotic patients: a quantitative magnetic resonance imaging study. Biol Psychiatry 1991;29:159-75.

34. Degreef G, Ashtari M, Bogerts B, et al. Volumes of ventricular system subdivisions measured from magnetic resonance images in first-episode schizophrenic patients. Arch Gen Psychiatry 1992;49:531-7.

35. Bilder RM, Lipschutz-Broch L, Reiter G, Geisler SH, Mayerhoff DI, Lieberman JA. Intellectual deficits in first-episode schizophrenia: evidence for progressive deterioration. Schizophr Bull 1992;18:43748.

36. Hoff AL, Riordan H, O'Donnell DW, Morris L, DeLisi LE. Neuropsychological functioning of firstepisode schizophreniform patients. Am J Psychiatry 1992;149:898-903.

37. Kenny JT, Friedman L, Findling RL, et al. Cognitive impairment in adolescents with schizophrenia. Am J Psychiatry 1997;154:1613-5. 
38. Pool D, Bloom W, Mielke DH, Roninger JJ Jr, Gallant DM. A controlled evaluation of loxitane in seventy-five adolescent schizophrenic patients. Curr Ther Res Clin Exp 1976;19:99-104.

39. Realmuto GM, Erickson WD, Yellin AM, Hopwood JH, Greenberg LM. Clinical comparison of thiothixene and thioridazine in schizophrenic adolescents. Am J Psychiatry 1984;141:440-2.

40. Lieberman J, Jody D, Geisler S, et al. Time course and biologic correlates of treatment response in firstepisode schizophrenia. Arch Gen Psychiatry 1993; 50:369-76.

41. Simeon JG, Carrey NJ, Wiggins DM, Rowane WA, Friedman L, Schulz SC. Risperidone effects in treatment-resistant adolescents: preliminary case reports. J Child Adolesc Psychopharmacol 1995;5:69-79.

42. Grcevich SJ, Findling RL, Rowane WA, Friedman
L, Schulz SC. Risperidone in the treatment of children and adolescents with schizophrenia: a retrospective study. J Child Adolesc Psychopharmacol 1996;6:251-7.

43. McConville B, Arvantis L, Wong J, et al. Pharmacokinetics, tolerability, and clinical effectiveness of quetiapine in adolescents with selected psychotic disorders. Schizophrenia Res 1999;36:289.

44. Keegan DL, Albright P, Petersen T. Long-term healthcare resource utilisation and costs before and after initiation of risperidone treatment in patients with chronic schizophrenia. Clin Drug Invest 1999; 18:233-7.

45. Davies MA. Parents of teenagers with psychosis. Presented at the Annual Meeting of the American Psychiatric Association, San Diego, May 1997:2. 